\title{
Experimental Study of Influence of Different Nozzle Configuration on a Heat Transfer in Jet Impingement
}

\author{
Bramhadev Bachute* and D. S. Watvisave \\ Department of Mechanical Engineering, Sinhgad College of Engineering, Pune-41, India
}

Accepted 15 June 2016, Available online 20 June 2016, Special Issue-5 (June 2016)

\begin{abstract}
Enhancement of heat transfer using the jets impingement on a surface and related fluid flow phenomenon developed due to turbulence is still an active area of research. In present study effect of different nozzle shapes on heat transfer with a plane surface is experimentally investigated. In this the Reynolds number is range in from 5000 to 15000 based on jet exit velocity and nozzle hydraulic diameter and nozzle to plate spacing (H/D) from 2-10 nozzle hydraulic diameter. The size of nozzle exit area is selected based on nozzle hydraulic diameter $7 \mathrm{~mm}$. It is found that heat transfer with square nozzle jet is more than other nozzle configuration and maximum heat transfer rate with square jet at $H / D=6$ are obtained.
\end{abstract}

Keywords: Heat transfer, Force convection, Fluid flow, Jet impingement

\section{Introduction}

Now a day's requirement of high power electronic components is increased and we required faster, smaller and reliable electronic components. Increasing in high power load on electronic component heat is generated cause a failure of system. To avoid this failure we need to cool electronic parts or microprocessor, for this various cooling method are used such heat sink, heat sink with fan, heat pipes, jet impinging cooling. Jet impinging cooling is one of the efficient solutions of cooling hot object in industrial processes as it produces very high heat transfer rate through the force convection. Jet impinging is widely used for cooling, heating and drying in several industrial applications due to their high heat removal rates with low pressure drop. There is large class of industrial processes such as cooling of turbine blades, the quench of product in the glass or steel industry and enhancement of cooling efficiency in the electronic industries. Jet impingement provide high heat transfer rate over a small area so it is widely used in different industrial applications but it gives high heat transfer rate for a short flow path. In this air is used as medium for cooling. Many researchers investigated fluid flow and heat transfer characteristics by impinging jet on smooth and flat surface.

\section{Literature Review}

A review on heat transfer data through a single circular jet is reported (Jambunathan, et al,) heat transfer

*Corresponding author Bramhadev Bachute is a PG Student and D. S. Watvisave is working as Professor coefficient in wall jet region is independent on nozzle to plate spacing up to $H / D=12$. Experimentation is carried out to study the effect of shape of nozzle (Circular, Square, Rectangular jet) on heat transfer distribution, Infrared thermal imaging technique is used to find heat transfer characteristics and found that heat transfer is insensitive to shape of nozzle(Gulati, et al. 2008).

The geometry of nozzle has considerable effect on heat transfer. In this they used square edge with chamfered and non-chamfered nozzle to investigate effect of nozzle geometry on heat transfer. They reported chamfered edge nozzle has no effect on heat transfer distribution (Attalla, et al). Heat transfer characteristics are evaluated at low nozzle to plate spacing with confined single round jet. Transient liquid crystal technique is used for heat transfer distribution evaluation (Oriana, et al, 2013).

The effect of nozzle diameter on heat transfer coefficient is investigated (Jacob, et al, 2013). Submerged air jet is used to investigate the fluid flow and heat transfer characteristics with a circular jet (Anwarullah et al, 2012) and they observed that Nusselt number increases with decrease in nozzle to plate spacing. The effect of flat plate and surface intended plate on a heat transfer is investigated (Jeevanlal et al, 2014) and the found that heat transfer is greater at intended surface than flat surface. Three different nozzle diameter $(5 \mathrm{~mm}, 10 \mathrm{~mm}, 20 \mathrm{~mm})$ are used to investigate the flow structure and heat transfer of normally impinging air jet (Rassol et al, 2014) and they was noticed heat transfer increase with increase 
in nozzle diameter due to modification in velocity at same Reynolds number. Heat transfer distribution is studied with dimpled or protrusion on target surface (Dafedar, et al),(beitelmal et al), they summarized as heat transfer is more for dimpled surface than plane surface.

The objective of this paper is to study the effect of different parameter such as Reynolds number and nozzle to plate spacing on a heat transfer characteristics with a three different nozzle configuration Circular, Square, Rectangular. The experimental parameters include jet to plate spacing (H/D) ranging from 2-10 and Reynolds number ranging from 5000 to 15000 .

\section{Experimental setup}

Schematic of air jet impingement system is shown in figure. In this air compressor is used to compress and store air at high pressure and pressure regulator valve is connected to regulate the pressure at 3 bars. Flow control valve is used to control mass flow rate of air. The air supplied through a orifice meter to a nozzle (Circular, Square and Rectangular) and air is imping on a plate normally. Stainless steel plate is used as target plate $(60 \mathrm{~mm} \times 60 \mathrm{~mm} \times 5 \mathrm{~mm})$ is used as heat sink material and heater with aluminum foil is used as same size of impinging plate is clamped to target plate tightly. Thermal images are obtained with thermal imaging camera (Testo 875) is used. This thermal imaging camera reads plate temperature based on emissivity of surface.

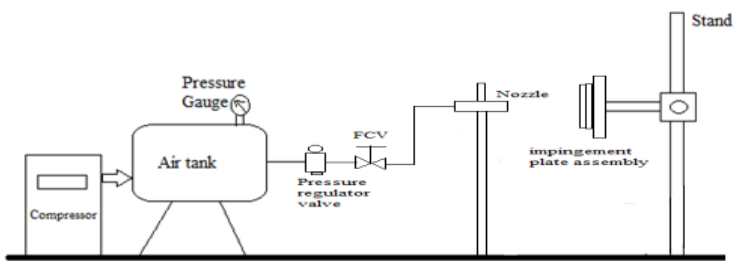

Fig. 1 Schematic of experimental setup

Dimmerstat and wattmeter are used to control the power supplied, the constant power is supplied to plate which is measured by wattmeter.

\subsection{Experimental procedure}

The experiments is conducted for different Reynolds number (varying mass flow rate) ranging from 5000 to 15000 and nozzle to plate distance (H/D) is also varying from 2 to 10 nozzle diameter.

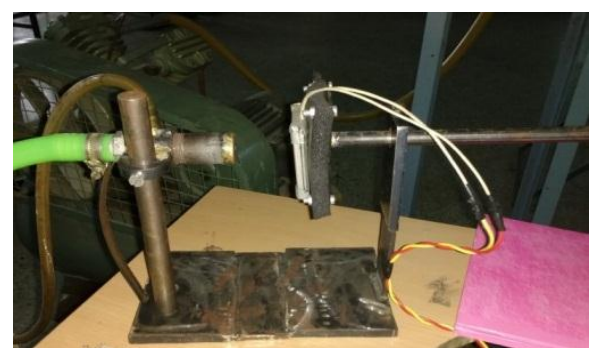

Fig 2 Actual Experimental Setup
The mass flow rate is kept constant and temperature readings are taken at different nozzle to plate spacing The variations in temperature measurement are $\pm 0.1^{\circ}$ C. Air is imping on a flat plate through a three nozzle configurations. The power supplied to plate is constant at $20 \mathrm{~W}$ measures by wattmeter and controlled by dimmerstat. The readings are taken at stagnation point (Centre of jet). Calculation of Nusselt number is done as per given below.

\subsection{Data reduction}

Nozzle exit Reynolds number is calculated by

$\operatorname{Re}=\frac{\rho V D}{\mu}$

Where - $\rho$ - Density of fluid, V - Velocity of air at nozzle exit, D - Hydraulic diameter of nozzle

Now Total power supplied is

$\mathrm{Q}=\mathrm{VI}$

Where V- Voltage supplied, I - Current supplied

$\mathrm{Q}=\mathrm{Q}_{\mathrm{cond}}+\mathrm{Q}_{\mathrm{conv}}+\mathrm{Q}_{\mathrm{rad}}$

$\mathrm{Q}_{\text {Conv }}=\mathrm{Q}-\left(\mathrm{Q}_{\text {Cond }}+\mathrm{Q}_{\mathrm{Rad}}\right)$

$\mathrm{Q}_{\text {Cond }}=\mathrm{K}_{\text {plate }} \mathrm{A}_{\text {plate }} \Delta \mathrm{T}$

Where

$K_{\text {plate }}$ - Thermal conductivity of plate

Aplate - Area of plate

$\Delta \mathrm{T}$ - Change in temperature per unit length

$\mathrm{Q}_{\text {Rad }}=\sigma \mathrm{A}_{\mathrm{S}}\left(\mathrm{T}_{\text {Plate }^{4}}-\mathrm{T}_{\infty}{ }^{4}\right)$

Where- $\sigma$ - Steffen Boltzman constant, As - Surface Area of plate

Heat transfer coefficient is calculated by

$\mathrm{h}=\frac{Q_{\text {Conv }} / A_{\text {plate }}}{T_{\text {plate }}-T_{\text {jet }}}$

Nusselt number is calculated as

$\mathrm{Nu}=\frac{h D}{K_{\text {air }}}$

Where - h- Convective heat transfer coefficient, DHydraulic diameter of nozzle, $\mathrm{K}_{\mathrm{air}}-$ Thermal conductivity of air.

\section{Result and discussion}

Experiment were conducted to study the effect of nozzle configuration on distribution of local heat transfer coefficient at varying nozzle to plate spacing $(\mathrm{H} / \mathrm{D}=2,4,6,8,10)$ and at five different jet exit 
Reynolds number 5000, 7500, 10000, 12500, 15000 based on nozzle hydraulic diameter and jet exit velocity.

\subsection{Effect of Reynolds number on Nusselt number}
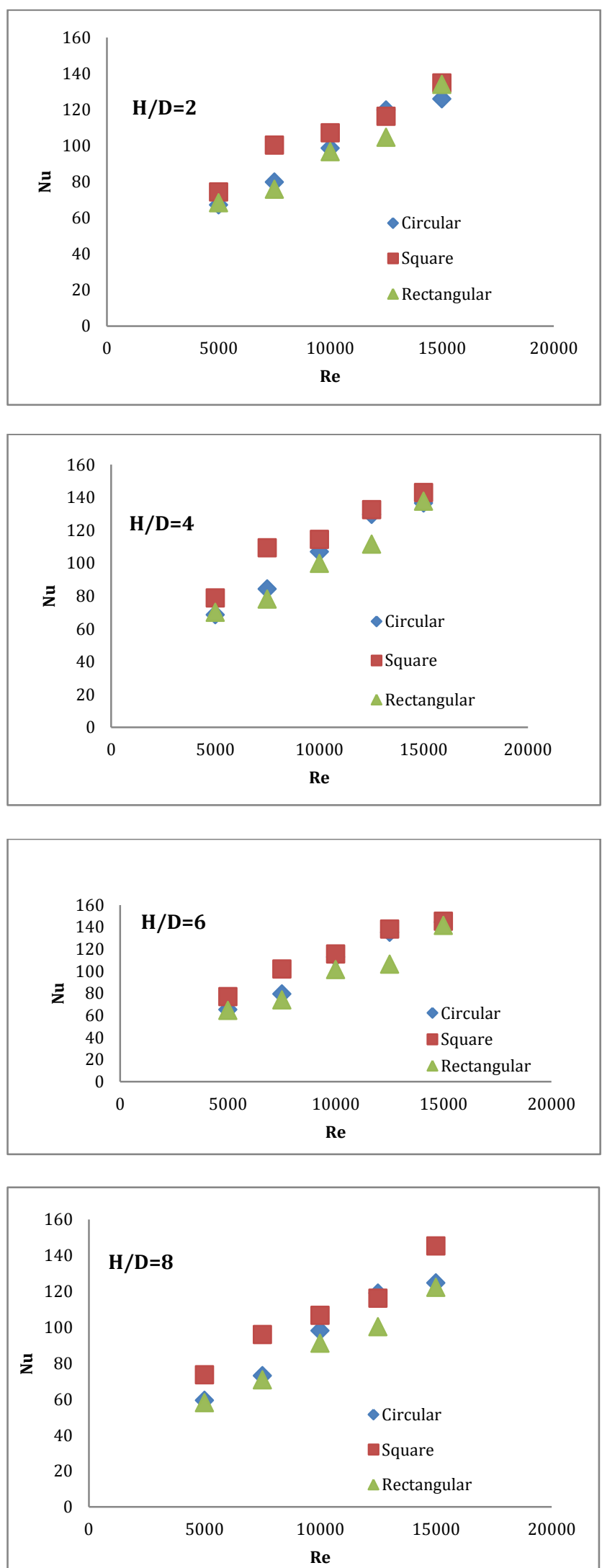

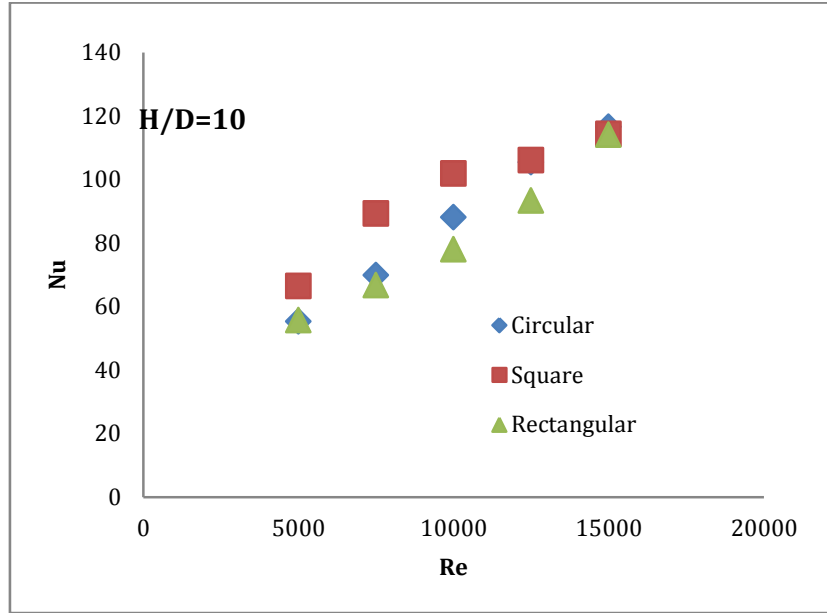

Fig 3 Effect of Reynolds number on Numsselt number at $H / D=2-10$ for circular, square, Rectangular Nozzle for different Reynolds number

Fig 3 shows effect of $H / D$ on the stagnation point Nusselt number at different Reynolds numbers for the Circular, Square and Rectangular jets. It is found that stagnation point Nusselt numbers increase with H/D from $\mathrm{H} / \mathrm{D}=2.0$ up to around $\mathrm{z} / \mathrm{d}=6.0$ and then slightly drop due to increase in turbulent intensity at the stagnation point with increase in $\mathrm{H} / \mathrm{D}$.

\subsection{Effect of nozzle to plate spacing on Nusselt number}
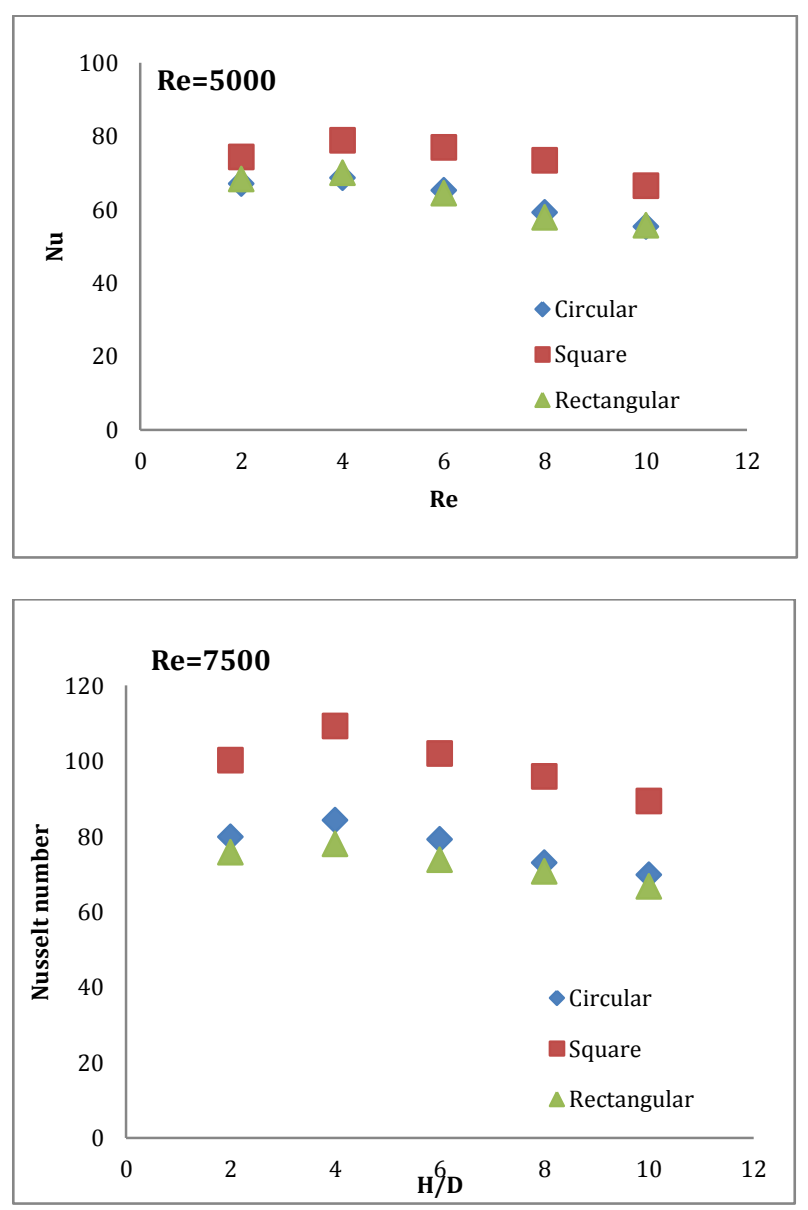

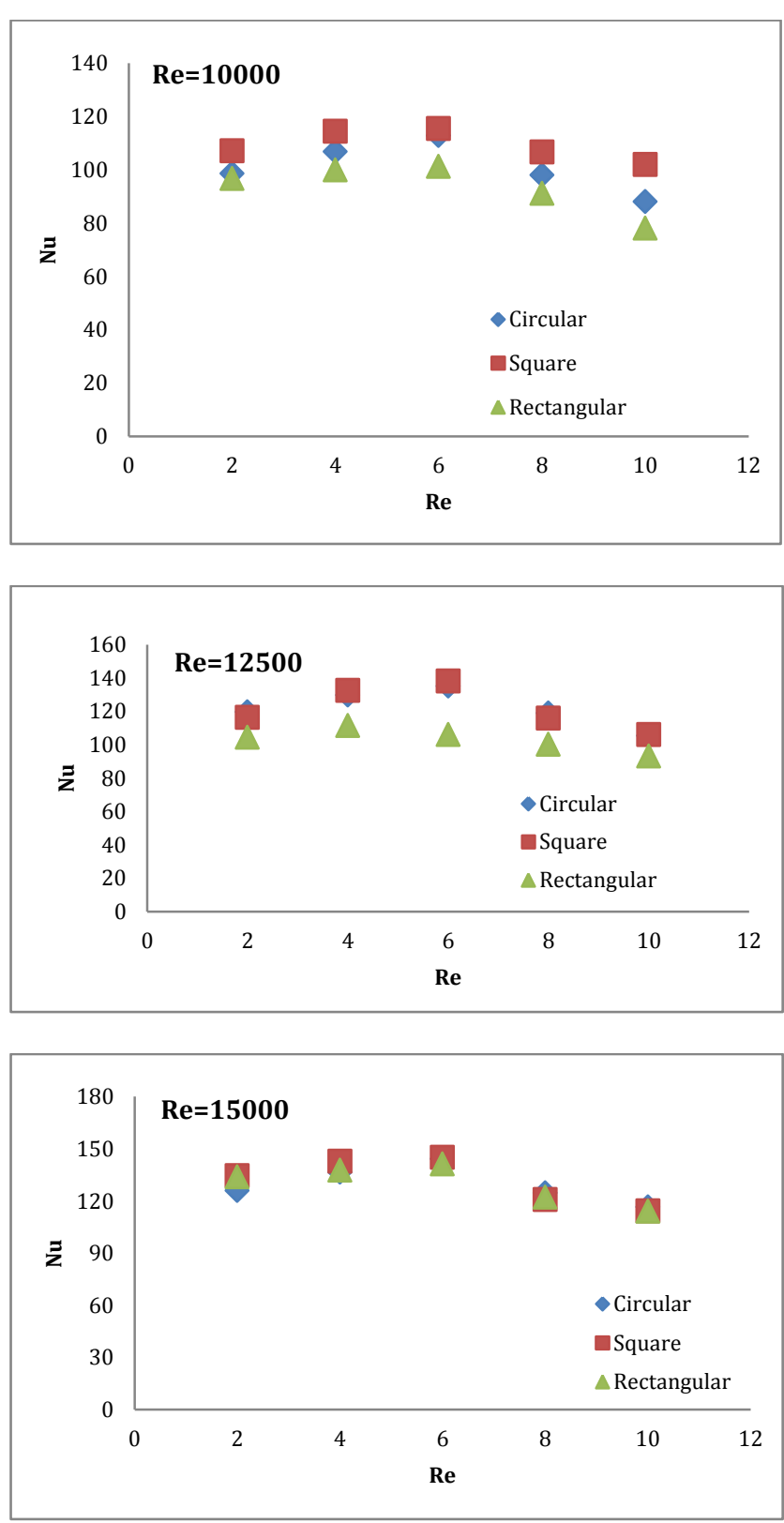

Fig 4 Effect of nozzle to plate spacing on Nusselt number

Fig 4 shows that effect of Reynolds number on Nusselt number at different nozzle to plate spacing and it is found that Nusselt number increases with increase in Reynolds number at a given $\mathrm{Z} / \mathrm{D}$ ratio. At higher Reynolds number, turbulence level increases and along with this spread of jet also increases. The amount of fluid that comes out of the jet is increases for higher Reynolds number which causes improve the heat transfer performance. The nusselt number increase as nozzle to plate spacing increases up to $H / D=6$ and then decrease sharply due to jet losses its axial velocity for higher $\mathrm{H} / \mathrm{D}$ ratio.

\section{Conclusions}

The effects of the different nozzle configuration (Circular, Square, Rectangular) on impinging jet heat transfer is experimentally investigated at different Reynolds numbers and nozzle-to-plate spacing.

1) Effect of Reynolds number with three nozzle configuration shows same heat transfer characteristics: as Reynolds number increases Nusselt number increase.

2) Heat transfer rate with Square jet is more as compared to Circular and Rectangular jet in the stagnation region.

3) Maximum nusselt number is obtained at $R e=15000$ and $\mathrm{H} / \mathrm{D}=6$ with Square nozzle

\section{References}

K. Jambunathan, E. Lai, M. A. Moss and B. L. Button,(1992) A review of heat transfer data for single circular jet impingement, International Journal of Heat and Fluid Flow, 13, 106-115.

P Gulati, V Katti, S.V. Prabhu, (2009) Influence of the shape of the nozzle on local heat transfer distribution between smooth flat surface and impinging air jet, International Journal of Thermal Sciences 48,602-617.

O Caggese, G Gnaegi, G Hannema, Terzis , A Peter,(2013) Experimental and numerical investigation of a fully confined impingement round jet, International Journal of Heat and Mass Transfer 65, 873-882.

A. Jacob, Leena R., Krishnakumar T.S., and J Prakash, (2012) Numerical and experimental investigations on jet impingement cooling, International Science Index, 7, 1049-54.

M. Anwarullah, V. Vasudeva Rao , K.V. Sharma,(2012) Effect of Nozzle Spacing on Heat Transfer and Fluid Flow Characteristics of an Impinging Circular Jet in Cooling of Electronic Components, International journal of Thermal \& Environmental Engineering, 7-12.

V.M.Jeevanlal , B.C. Anil Kumar,(2014) Experimental Investigation of Heat Transfer from a Flat and Surface Indented Plate Impinged with Cold Air Jet- Using Circular Nozzle, International Journal of Emerging Engineering Research and Technology, 160-170.

Adnan A. Abdul Rasool a, Jirunthanin V. b, F. A Hamad, Numerical and experimental study of flow structure and cooling behaviour of Air Impingement on a Target Plate, International Journal of Thermal \& Environmental Engineering, 33-43.

M.A.Dafedar , Mujtabalayeeq , M Taher, Shahid,(2013) Heat transfer enhancement through different circular diametrical dimple surface under forced convection an experimental approach, International Journal of Research in Engineering and Technology, 168-175. 